\title{
SUPPORTING THE DEVELOPMENT OF BUSINESS ENVIRONMENT THROUGH ECONOMIC ORDER POLICY
}

\section{IRAKLI ASLANISHVILI}

\section{PHd student}

Ivane Javakhishvili Tbilisi State University, Georgia

irakli.aslanishvili@gmail.com

KEYWORDS: BUSINESS ENVIRONMENT, ECONOMIC POLICY, GOVERNMENTAL REGULATIONS, CURRENCY EXCHANGE RATE, COURT SYSTEM, LEGISLATION ENVIRONMENT, TAX POLICY.

For citation: Aslanishvili I. (2019), Supporting The Development Of Business Environment Through Economic Order Policy, Globalization And Business, №7, pp. 163-167. https://doi.org/10.35945/gb.2019.07.020

\section{INTRODUCTION}

As a policy that determines qualitative changes in the economy, economic order aims to establish a framework for economic activities in the public and private sectors and to adapt the said activities to the social, economic and technological processes [Streit 2005, pp. 26-30; 49-53].

Within the economic order policy, there is a conflict between the social and competitive orders. The competitive order is success-oriented, while the social order is aimed at satisfying requirements, which conflicts with the principle of success at least in part (Gvelesiani, 2018: 163-166).

On the one hand, therefore, the state tries to form and expand the limits of social order within the economic order policy, while on the other hand, the market is designed to establish a viable and competitive order and enable its implementation. Establishing suitable areas for public (social order) and private (competitive order) economic activities and setting rational boundaries between them is crucially important for the entrepreneurship development strategy. In countries where such areas and boundaries are properly established, small, medium-scale and large enterprises are achieving success on domestic and international markets by 'taking over' the relevant segments and retaining leading positions in the long term (Gvelesiani and Gogorishvili 2018:12).

The issue of regulations has become increasingly topical in Georgia, be it the property rights, product quality, antidumping measures, anti-dumping legislation or labour laws. We may sometimes think that certain regulations do not affect us directly, but this is a false view - there are no regulations that are 'worthless' to the public. We all pay towards them, and we naturally wish to get a product of suitable quality in return. In order to obtain good regulations, we need to answer the following question: what should we regulate, and how?

In response to the aforementioned question, most developed countries, such as the United States and the European Union member states, turn to a rather difficult and labour-intensive process of regulatory impact assessment (RIA), which requires a systematic study of its necessity, benefit and cost. On the one hand, state regulations are a useful tool for achieving government objectives, yet on the other hand, each regulation has a broad range of impact. Identifying potential harmful effects in various areas is difficult without a RIA. Ideal regulations ought to be proportionate to their objectives and economically balanced. In order to obtain good regulations, we must assess both their effectiveness and their expediency. Effectiveness alone is not sufficient.

A regulation is not an end in itself, but a means to an end. Its objective must be clear and attainable. Last year, the Parliament of Georgia initiated legislation on labour migration which was to impose certain bureaucratic barriers and restrictions on employment of foreign nationals in Georgia. Naturally, imposing such restrictions cannot constitute an end in itself. Restricting the employment of foreigners will not automatically increase the interest of employers towards the local labour market. Most employers decide to invite foreign specialists only when they cannot source suitably qualified personnel locally (incurring additional expenses for the company). At the same time, the disbalance between supply and demand on the market cannot 
be eliminated through such restrictions. In this particular case, the legislators took the views of the stakeholders on board and did not bring this regulation into force. However, in the absence of RIA, there is no guarantee that they will always act in such a reasonable manner.

In most cases, regulations impose new obligations on certain sections of the public (individuals or businesses). Naturally, complying with these regulations requires new or higher costs that are usually born both by the supplier of the product or service and by the consumer (Hayek, 1979: 128). An overly strict and 'costly' regulation has an even further-reaching effect, as it disproportionately affects the competitive environment. Nevertheless, introduction of RIA does not in itself guarantee harmlessness of regulations. The precise integration point of this tool in the government vertical is of crucial importance. Experience shows that the higher it is integrated institutionally, the more effective and compliant it is with the government's declared priorities.

Appropriately implemented RIA procedures significantly improve the government's decision-making culture, ensure transparency of the process and involvement of all stakeholders that may be affected by the relevant regulations, be they specific state bodies or individual groups. Ensuring RIA's success requires not only coordination and clear expression of political will at top level, but also the formulation of uniform standards and criteria that must be satisfied by all regulations. It is also necessary to systematize sources of information and implement a monitoring system. Subordination of regulatory decisions to the overall state policy and coordination between various branches of government is particularly important for economic policymaking. Otherwise, the process of forming a predictable and sound business environment is doomed to failure. We simply do not have the luxury to be able to introduce ill-thought-out regulations. Establishing an attractive business environment and attracting foreign direct investment is one of Georgia's main opportunities, if not the only one.

The Georgian Business Environment through the Eyes of the Private Sector study identifies and assesses the major issues that are currently considered as most pressing by the private sector in general, and by members of the Business Association of Georgia (large companies operating in Georgia) in particular. The most serious obstacles highlighted by the private sector are as follows: fluctuating currency exchange rates; the judiciary system; unpredictable changes in the regulatory environment; and labour resources. It is also interesting to note the private sector's opinion about the effectiveness of state institutions. The study shows that the private sector sees the central government as more effective than local self-government units and municipalities. With regards to dealing with public institutions, companies are most concerned about delays and decision-making. The results of the interviews are supported by quantitative research. Private company representatives state in the interviews that communication with the government is good, but post-communication (decision-making) stages are drawn out.

The existing tax environment in Georgia is seen highly positively by the private sector. Companies provide positive assessment not only of the tax policies and rates but also the administration of taxes, noting that there has been significant improvement in the latter component over the last three years. Several aspects of the tax environment were analysed and evaluated positively.

In spite of the challenges and problems identified by the study, the private sector has positive expectations. Most companies plan to grow and expand over the next 3-5 years. Overall, the private sector views the existing business environment positively and believes it to be favourable for day-to-day activities and long-term development. Georgian Business Environment through the Eyes of the Private Sector is an important analytical study carried out by the Business Association of Georgia (BAG). Through its economic reports and analytical publications, BAG enables informed decisionmaking in the private and public sectors. This study is of particular interest to policy-makers, as it presents the private sector's views on a wide range of issues, from macroeconomics to the effectiveness of bureaucracy.

\section{METHODOLOGY}

Various research methods were used in this article - specifically, those of induction, analysis, assumption, scientific generalisation, comparative analysis, data analysis, as well as investigative evaluation methods.

The Georgian Business Environment through the Eyes of the Private Sector study was carried out by my leadership in three stages. First, surveying works were carried out to identify the elements of the business environment and its challenges in full. Qualitative research was carried out during the second stage, the results of which formed the basis for quantitative research during the third stage.

The first stage involved studying international research and publications, as well as detailed analysis of the information accumulated over many year's of BAG's activity. This information was used to plan the structure and objectives of interviews for the second stage. Owners and heads of 44 BAG member companies were surveyed for the qualitative study, which was carried out with the help of in-depth face-to-face interviews. Questionnaires for the interviews were prepared in advance, and addressed the issues that are important to the business community. The goal of the qualitative study was to identify the main concerns of the private sector and test the hypotheses prepared on the basis of prior practice or the existing literature.

The third stage of research made use of the results of the qualitative study to devise a quantitative questionnaire for 40 BAG member companies. This aim at this stage was to provide quantitative assessment of the private sector's attitudes 
towards the elements of pressing importance for the business environment and the major problems facing the sector.

\section{AREA OF RESEARCH}

BAG member companies formed the target group for the Georgian Business Environment through the Eyes of the Private Sector study. These are large Georgian and international companies operating in Georgia. As they form a significant part of the Georgian economy, by examining their positions we can get a good picture of the general mood in the private sector, learn what the sector's expectations are and where it sees threats to its development and stability.

\section{RESEARCH RESULTS}

On the basis of qualitative and quantitative research, the Business Association of Georgia identified the most topical issues for the business environment. The most pressing issues for the private sector are currently as follows: the state economic policy; the tax environment; international relations; the judicial and regulatory environment; the courts and the alternative conflict resolution mechanisms, state institutions; public procurement; finances; and the labour market.

Having identified the main areas of research, the private sector's attitude towards various sub-components was analysed. In-depth interviews revealed the most significant areas for the Georgian business community, while the quantitative survey ranked these issues based on their importance. The results are shown in detail below.

The private sector identified the fluctuating currency exchange rate as the most topical and pressing issue, followed by the judiciary and the unpredictable changes in the regulatory environment. The full list of issues in order of their importance is as follows: the fluctuating currency exchange rate; the judiciary; the unpredictable changes in the regulatory environment; regional affairs (in neighbouring countries); the labour market; infrastructure; bureaucracy in central government institutions; bureaucracy at municipal level; tax environment; access to finances.

\section{CURRENCY EXCHANGE RATE}

The fluctuating exchange rate had a certain negative effect on $95 \%$ of the surveyed companies over the last year. Respondents stated that sharp fluctuations in a short period of time were particularly damaging for their business [Business Association of Georgia, 2017 Study].

\section{JUDICIARY}

The private sector identified the judiciary as the secondmost pressing problem, with $44.7 \%$ of the respondents rating the quality of the current system as 'unacceptably poor,' $34.2 \%$ as 'poor,' $18.4 \%$ as 'satisfactory,' and only $2.6 \%$ as 'good.'

Individual components of the judiciary, such as the impartiality of courts, competence, the efficiency of conflict resolution and the effectiveness of the judicial apparatus were also assessed in the study. The efficiency of conflict resolution was identified as the gravest problem by the private sector, with $54 \%$ of the companies rating it as 'unacceptably poor.' $51 \%$ of the respondents believe that competence levels in the judiciary are low. Furthermore, $43 \%$ also rated court impartiality as 'low.' Significantly, none of the components of the judiciary were rated highly by the respondents [Business Association of Georgia, 2017 Study].

\section{LEGISLATIVE ENVIRONMENT}

As mentioned earlier, BAG members see unpredictable changes in the regulatory environment as one of the main problems. The majority of respondents rated the existing legislative/regulatory environment negatively, with $44 \%$ stating that it hindered long-term development, while $24 \%$ believed that it also restricts day-to-day activities [Business Association of Georgia, 2017 Study].

We tried to establish the specific problems most frequently encountered by businesses in the legislative/ regulatory environment, and found that ambiguity and incoherence of laws and regulations constitutes the main problem for the majority of respondents, followed by the incompatibility the laws and regulations with their needs. Notably, $20 \%$ of companies did not identify any significant problems in the legislative/regulatory environment.

\section{PROBLEMS WITH LEGISLATION/REGULATIONS}

The survey asked the respondents to name the specific laws or legislative norms, the introduction/changes to which affected their business negatively over the last three years. This was an open question, and the most frequently stated answers included changes to the Labour Code, changes to the Law on Land Ownership and the unexpected changes to the Tax Code (more specifically, making advance payments subject to VAT).

\section{BUREAUCRACY}

The qualitative study revealed that the private sector sees timely and effective decision-making as one of the main challenges in state governance. It believes that the government is open in its relationship with the private sector, is prepared to take the latter's ideas and initiatives on board and look for best ways to resolve problems. The obstacles present themselves at the following stage, when it comes to making decisions and taking specific measures to resolve the issues.

It was interesting to see the private sector's assessment 
of individual state institutions. More than 20 such institutions were evaluated in the study, with the Ministry of Finance and the Ministry of Economy and Sustainable Development receiving the highest marks. Notably, only a negligible part of the respondents (1-2\%) rated the public institutions as either 'very good' or 'unacceptably poor.' The most prevalent rating was 'satisfactory.' The private sector believes that there is a significant room and need for improvement in the public sector (Business Association of Georgia, 2017 Study).

The study aimed not only to obtain a general assessment of the state institutions, but also to learn about the problems most frequently encountered by the private sector in their relations with these institutions. 'Drawn-out processes' and 'drawn-out decisions' were identified as the most frequently encountered issues, followed by 'unpredictability of policy' and 'lack of competence.' On a few occasions, 'rudeness in communication' and 'lack of communication' were identified as problems. As we can see the findings of the qualitative study were backed up by the quantitative study - the private sector encounters obstacles when it comes to decisionmaking and enforcement of decisions.

\section{TAX ENVIRONMENT}

The tax environment is one of the most crucial components of the business environment across the world, and Georgia is no exception. Nevertheless, tax issues were not among the most pressing problems identified by the private sector, which suggests that the tax policies and administration are viewed favourably. This was confirmed by respondents during the interviews. They believe that the country has a good tax policy and the administration component is also constantly improving.

The Georgian tax environment was also positively assessed in the quantitative analysis, with $68 \%$ of the surveyed companies believing that it is good for long-term development, while $32 \%$ also think that it is favourable for day-to-day activities. $35 \%$ see the tax environment as predictable. Only $6 \%$ of the respondents see the tax environment as an obstacle to the private sector (Georgian Business Environment through the Eyes of the Private Sector, 2017).

\section{CONCLUSIONS}

The study has identified problems that can mostly be resolved through the involvement of other economic policymaking stakeholders. Results show that pressing issues highlighted by the private sector include the judiciary and the unpredictable changes in laws and regulations. Judicial reforms have long been a subject of discussion, but they are not proceeding quickly enough. This creates a serious threat to the investment climate in Georgia. Failure to resolve this problem increases the level of mistrust towards the system and exacerbates the existing problems within the system itself. Ultimately, this will have a negative impact on the country's economy.

With regards to the unpredictable changes, the private sector has been highlighting the need for a regulatory impact analysis and implementing rational regulatory procedures for numerous years. The study has once again underlined the need for such reforms.

Attention should also be paid to the fact that drawnout processes and decisions have been identified as a major problem in relation to state institutions. Significantly, the private sector encounters this problem in its dealings with both the central and the local authorities. Due to the pressing nature of the issue, we believe that we need to conduct a detailed study into the causes of these delays and learn whether this issue can be resolved by streamlining processes, increasing the levels of competence, or through other means.

\section{REFERENCES:}

1. Hayek, F.A. (1979). Law, legislation and Liberty, Volume III - The Political Order of a Free People, Chicago, London, reproduced in: Vanberg, V. Hayek Gesammelte Schriften bd. B4, Recht, Gesetzgebung und Freiheit, Tuebingen 2003.

2. Hayek, F.A. (2003), Rechtsordnung und Handelnsordnung, in: Streit, M.E. Hayek Gesammelte Schriften Bd. A4, Rechtosordnung und Haldelnsordnung, Tuebingen, p. 217.

3. Streit, M.E. (2005), Theorie der Wirtschaftspolitik, 6. Edition, Stuttgart.

4. Gvelesiani, R., Gogorishvili, I. (2012). Compatibility of Economic and Political Decisions with Core Social Values. Tbilisi.

5. Gvelesiani, R., Gogorishvili, I. (2018). Decision-Making Technology in Economic Policy. Tbilisi.

6. Gvelesiani, R. (2017). Discrepancies between the Main Social Values and the Problem with overcoming them. Economy and Business Journal, Vol. X\#1, Tbilisi.

7. Gvelesiani, R. (2018). The Problem with Creating a Specific Framework for Economic Order. In 1st International Conference on Challenges of Globalisation in Business and the Economy materials, Tbilisi.

8. Georgian Business Environment through the Eyes of the Private Sector (2017). - Business Association of Georgia, October 2017. 


\section{SUPPORTING THE DEVELOPMENT OF BUSINESS ENVIRONMENT THROUGH ECONOMIC ORDER POLICY}

\section{IRAKLI ASLANISHVILI}

\section{PHd student}

Ivane Javakhishvili Tbilisi State University, Georgia

irakli.aslanishvili@gmail.com

KEYWORDS: BUSINESS ENVIRONMENT, ECONOMIC POLICY, GOVERNMENTAL REGULATIONS, CURRENCY EXCHANGE RATE, COURT SYSTEM, LEGISLATION ENVIRONMENT, TAX POLICY.

For citation: Aslanishvili I. (2019), Supporting The Development Of Business Environment Through Economic Order Policy, Globalization And Business, №7, pp. 55-167. https://doi.org/10.35945/gb.2019.07.020

\section{SUMMARY}

The goal of this study is to analyse the impact of economic order policy on the development of the business environment, as well as to learn about the private sector's current assessment of the existing business environment, the problems and challenges encountered by the private sector, and the areas on which the efforts ought to be focused. Study team grouped and leaded by me has examined the attitudes of members of the Business Association of Georgia (BAG) towards all major elements of the business environment.

The aim of my study is to use the results to devise BAG's future advocacy campaigns. It is planned to present the results of the study to all major parties involved in devising economic and business policies to ensure that they are familiar with the private sector's vision and are able to take it into account when working on economic policies. 